\title{
Lifestyle change in the cancer setting using 'the teachable moment': protocol for a proof-of-concept pilot in a urology service
}

\author{
Alyssa Sara Lee ${ }^{1,2}$, Gozde Ozakinci $^{2^{*}} \mathbb{D}$, Steve Leung ${ }^{1}$, Gerry Humphris ${ }^{2}$, Hannah Dale ${ }^{2,3}$ and Neil Hamlet ${ }^{4}$
}

\begin{abstract}
Background: Previous research has shown diagnosis or screening for cancer may be a 'teachable moment' for prevention through lifestyle change. Previous trials have been successful but have been delivered via national programmes targeting patients being screened for colorectal cancer. This manuscript reports the protocol for a proof-of-concept study to assess the feasibility and acceptability of a lifestyle change service targeting men suspected or diagnosed with cancer of the prostate in a secondary care cancer service within the UK.

Methods: Lifestyle change will be promoted through integration of a lifestyle change service in a urology department in one NHS Board. The service is delivered by a Health Psychologist and uses motivational interviewing and behavioural change techniques to motivate and support patients to consider and address topics such as increasing physical activity and a healthy diet, smoking cessation, alcohol reduction and weight loss. A service evaluation will assess feasibility and acceptability via a patient experience survey, a survey exploring staff knowledge, attitudes and practice, pre- and post-intervention lifestyle behaviour survey and an audit of routine patient database.

Discussion: This pilot will assess the viability of using cancer testing and diagnosis as a teachable moment for lifestyle change in a unique population (i.e. men with suspected cancer of the prostate). If successful, this approach offers potential for preventative services to enhance routine and person-centred clinical cancer care provided within secondary care settings.
\end{abstract}

Keywords: Lifestyle change, Men, Cancer, Teachable moment, Behaviour change, Protocol, Activity, Diet, Alcohol, Smoking

\section{Background}

Research suggests that up to four in ten malignant tumours could be prevented through lifestyle and other environmental changes [1]. Globally, if these preventive approaches could be introduced, this would represent a major reduction in disease burden, improve population health, and reduce health services costs [2]. As part of the varied intervention approaches to tackling this issue, lifestyle change programmes situated within secondary care cancer services are an important consideration.

\footnotetext{
* Correspondence: go10@st-andrews.ac.uk

${ }^{2}$ School of Medicine, University of St Andrews, Fife, St Andrews, Scotland KY16 9TF, UK

Full list of author information is available at the end of the article
}

Previous research has shown that diagnosis or screening for cancer may be a 'teachable moment' for prevention. Although conceptualised in different ways in the literature, teachable moments are considered to be opportunities or contexts/events representing an increased desire, willingness or capacity for change in patients [3, 4]. Hospitalisations (or interactions with hospital settings) and/or health conditions that are potentially 'life-threatening' are those most associated with spontaneous lifestyle change efforts among patients [3].

Cancer of the prostate (CAP) is the most common cancer among men in the United Kingdom (UK), accounting for $25 \%$ of all new cancers in males [5]. In 2012, there were 43,436 new cases of prostate cancer. The incidence of prostate cancer has increased since the late 1970 s due in part to improved detection of the 
disease through prostate-specific antigen (PSA) testing. Such a test and/or a positive diagnosis may offer a so-called teachable moment for lifestyle change.

Lifestyle change is particularly relevant to men with or undergoing investigations for prostate cancer. The World Cancer Research Fund [6] recently published strong evidence for increased risk for developing advanced cancer of the prostate who are overweight/obese. Key health behaviours, which are amenable to change via lifestyle interventions (e.g. changing diet, physical activity, smoking and alcohol consumption), contribute greatly to obesity, other serious health conditions and shortened lifespan. General population tend to have poor levels of awareness and understanding of the relevant contribution of lifestyle in cancer risk [7, 8]. It is possible that knowledge regarding the importance of prevention through lifestyle change is particularly low among men seeking input from secondary care for suspected cancer compared to women.

Previous research has found that many men being tested for suspected cancer of the prostate display relevant risk factors $[9,10]$. Lifestyle change can improve outcomes in this group [11, 12], but significant challenges remain. Men often experience barriers to accessing behavioural change advice and support [13]. Older males (especially those with lower educational status) are less likely to spontaneously change and/or proactively seek lifestyle support in relation to a cancer screen or a cancer diagnosis [13]. Furthermore, Larsen et al. [14] and Anderson et al. [15] argue that in the course of interactions with the health service, and in particular when a negative result is given to a patient being tested for a serious health condition, the absence of lifestyle change advice and support could be seen as endorsing current behaviour. The so-called health certificate effect may negate any heightened experience of risk or vulnerability arising from the context. Hence, the opportunity presented by a cancer test or diagnosis for developing patients' motivation for change may be squandered (see work on colorectal cancer conducted by Stead et al. [8] and further studies below).

Previous research utilising the teachable moment concept has been successfully conducted in a cancer screening settings [16]. Most studies of this nature in the UK have been conducted in colorectal cancer possibly because of the centrally coordinated national screening programme [17-20]. Craigie and colleagues [17] found significant weight loss over a 12-month period, among men and women, undergoing three face-to-face consultations and monthly phone calls implementing a teachable moment intervention. This intervention consisted of colorectal cancer screening, motivational interviewing and behavioural change strategies targeting diet and physical activity. Other relevant clinical indicators also improved, and there was evidence of high feasibility and acceptability (e.g. high recruitment and retention rate, low per-patient intervention cost and proportionate uptake from across a range of socio-demographic groups). Despite this success, there are translational issues into existing secondary care cancer settings. Suggested reasons for poor uptake include lack of clinician and service commissioner preparedness for introducing the lifestyle advice in routine testing and treatment settings within secondary care [15].

Current UK and European guidelines do not advocate screening for CAP. The pros and cons of this are outwith the scope of this article and are discussed here [21]. However, similar to the successful work carried out in relation to the UK national colorectal cancer screening programme, a biopsy for suspected CAP or a diagnosis could potentially be utilised as a teachable moment for lifestyle change in secondary care cancer settings. To date, little is known about the potential feasibility and acceptability of this approach in these settings. If successful this approach has wide applicability across cancer services more broadly.

\section{Aims and objectives}

The aim of the current study is to assess the feasibility and acceptability of a lifestyle change service targeting men suspected or diagnosed with CAP within a secondary care cancer service (urology) in the UK. The National Health Service (NHS) Urology Service offers diagnostics and treatment for men suspected with or diagnosed with prostate cancer. Diagnostics involve imaging and invasive procedures. Treatments options are varied but can involve major surgery, radiotherapy, chemotherapy or hormone therapy.

The lifestyle change service encompasses the following elements: it is integrated into existing participant treatment pathways (i.e. treated as a routine offer in the context of diagnostics/treatment); with access to patient information (exchanged via clinical systems, notes and through relationships with consultants and clinical nurse specialists (CNS)); assessment of lifestyle behaviours is conducted and normalised for patients; all potentially eligible patients (see criteria below) are invited at a specific moment to receive at least one face-to-face, one-to-one lifestyle consultation with a Health Psychologist (AL) who provides subsequent appointments as required. Finally, liaison with secondary and primary care colleagues is built into the service to enhance behavioural change and/or support a more holistic cancer care service. The development of the lifestyle change service and the associated evaluation is a proof-of-concept pilot. In other words, it is designed to identify whether a lifestyle change service, utilising teachable moments, can be integrated into routine cancer services for men with suspected, or diagnosed with, cancer of the prostate and has the potential for effecting positive change in this group and 
within the service. The specific objectives for this evaluation are to describe, assess and report:

1. Acceptability indicators

(a) Uptake to the service from men with a negative cancer screen

(b) Uptake to the service from men with a positive cancer screen

(c) Difference in uptake using socio-demographic and clinical characteristics of patients

(d)Consent for service evaluation

(e) Patient experience and satisfaction with the service

2. Feasibility indicators

(a) Number and duration of appointment(s) with a Health Psychologist

(b)Number and type of behaviours discussed

(c) Number of lifestyle change goals set

(d)Length of time taken to compose letters

(e) Changes to health behaviours made as a result of the consultation

(f) Clinical staff knowledge, attitudes and practices regarding lifestyle change practice

\section{Methods/design}

\section{Setting}

The setting is a urology service within a Scottish secondary care site in one NHS Board. The service provides diagnostics and treatment for benign and malignant urological disease to a population of 380,000 . In this NHS Board, 250 new prostate cancer diagnoses were made following approximately 500 prostate biopsies in 2014 [22].

The procedures for patients suspected of cancer of the prostate in this NHS Board are as follows: usually, patients undergo PSA testing and/or report relevant symptoms to their general practitioner within a primary care setting. If a specialist opinion is required, the patient is referred to the urology service in the secondary care setting. Specialist diagnostic investigations usually involve a transrectal ultrasound (TRUS) guided biopsy of the prostate or magnetic resonance imaging (MRI) of the prostate. The TRUS biopsy procedure is carried out by Consultant Urologists. The prostate cancer CNS co-ordinate appropriate adjunct investigations and provide patient support throughout the cancer pathway.

\section{Design}

The study is a proof-of-concept pilot. The service evaluation will use a mixture of methods to assess feasibility and acceptability of a teachable moment intervention for lifestyle change within this novel setting. This includes a patient experience survey, a staff experience survey exploring knowledge, attitudes and practice, a lifestyle survey (pre- and post-intervention patient lifestyle behaviour change survey) and an audit of routine patient data collected for service feasibility and delivery outcomes.

There is no control group. This is a service evaluation rather than a pilot trial.

\section{Participants}

All male patients referred to the urology service with a suspicion of cancer of the prostate, who undergo a TRUS biopsy of prostate, will be invited to participate in the intervention and service evaluation. Men who have been diagnosed with low-grade cancer of the prostate and who have made a treatment decision to proceed on an active surveillance protocol will also be invited to participate in the service and evaluation. Active surveillance is the postponement of immediate treatment, with definitive treatment provided if there is evidence that the patient is at increased risk for disease progression.

\section{Intervention}

\section{Procedures for the intervention}

All patients will be invited to receive at least one face-to-face, lifestyle consultation with a Health Psychologist. Consultations will run at the hospital clinic and are expected to last between 30 and $90 \mathrm{~min}$. The intervention will be individualised for all patients who come through the service but will include some key features (see details below). Patients will be advised that they can bring a spouse or other supporter/family member.

Where possible, appointments will run immediately after seeing the CNS for TRUS biopsy results (2 weeks following biopsy), if patients are to be given a negative result. The CNS will ask patients if they are willing to participate in the new service. Patients will already have been 'primed' to expect this through a letter which explains the importance of their lifestyle as part of their urology care. A pre-procedure lifestyle survey is also included (see procedure for evaluation below), which all patients will be invited to complete before attending the biopsy appointment. When the Health Psychologist is unavailable on the day of the results clinic, a follow-up telephone call will be made to arrange an appointment.

Men who receive the active surveillance protocol will be sent a hospital letter advising them to contact the service to make an appointment for a lifestyle consultation. Patients who pro-actively contact the service will be followed up to arrange an appointment with the Health Psychologist. 


\section{Consultation style and content}

Consultations will start with rapport building plus a discussion of the role of the Health Psychologist as part of the wider urology team and will use a combination of approaches to discuss and prompt lifestyle change efforts. This will include using motivational interviewing (MI) [23] and behavioural change techniques (BCTs), taken from the taxonomy of BCTs [23]. The theoretical underpinnings of $\mathrm{MI}$ and BCTs are well understood [23, 24].

MI is defined as 'a directive, client-centered counseling style for eliciting behavior change by helping clients to explore and resolve ambivalence' ([24] (para. 3)). Although the focus of the consultation will be patientcentred (e.g. if they raise a concern about their weight) in keeping with the goal-directed nature of MI, it will also be monitored by the Health Psychologist who will seek to use the consultation to explore and resolve ambivalence about making relevant lifestyle changes. In keeping with MI, resistance will be met with reflective statements and emphasis on personal agency of the patient, especially regarding uncertainty and ambivalence about changing. Difficult and competing emotions associated with making a change will be normalised and empathy expressed with the patient experience. The importance of quality of life and long-term goals for health will be raised by the Health Psychologist to match patients' concerns that are raised (e.g. positive health is promoted and not just a lack of illness). Patients will be advised that looking holistically at all aspects of their lifestyle is important for the team to help identify areas where changes could be made to improve their own personal outcomes (e.g. quality of life) in addition to improving health outcomes. Some examples will be used, such as stopping smoking and increasing exercise. Patients will be explicitly advised that the consultation will follow their agenda for lifestyle topics focusing on what patients noticed from their completed lifestyle survey and/or what they had heard about the role of lifestyle in cancer prevention and treatment. Efforts will be made to socialise patients to a collaborative approach as distinct from their usual expectations of secondary care appointments which follow a more traditional medical model. This will be achieved through agreeing goals together, asking patients for their views and problem-solving before devising detailed behaviour change suggestions are made. Sometimes there will be an explicit, open discussion to contrast deliberately this approach with that of previous medical encounters that the patient may have experienced. Emphasis will be placed on participants as the judge of what is right for them in deciding to make a lifestyle change attempt.

Therefore, the conversational style, or approach, to the consultation will follow a MI framework. BCTs will be drawn upon within this style to bring further evidence-based intervention approaches to the consultation.
Discussions will include some, or all, of the following $\mathrm{BCTs}$, depending on the appropriate use of the BCT in the context of the patients' presentation: evidencebased information provision on recommendations for cancer prevention (or overall good health) when the participant has indicated they want it or are open to this information. Where indicated, patients will be given or shown credible written information (e.g. European code on Cancer Prevention, World Cancer Research Fund information). Individualised information will be used by highlighting or affirming patients' existing knowledge regarding positive lifestyle behaviours. Past experiences of successful behavioural change will be highlighted and affirmed. Efforts will be made to identify what made those changes successful to raise patient self-efficacy for new change attempts. Furthermore, patients will be asked what outcomes they experienced from changing (e.g. felt fitter, better, received compliments) or in the absence of such experience what they imagined they would experience if they made a change. In some cases, patients will make a commitment to make one or more behavioural changes. This could occur at the first appointment (where the assessment is conducted and the intervention begins or during later sessions if warranted). Usually, change goals will be developed using a written booklet (materials that had been previously developed by a Health Psychologist for NHS Fife, such as healthy eating action plans and physical activity plans). Patients will be expected to set between one and four specific goals (e.g. reduce alcohol consumption by having one to two alcohol free days per week, lose $20 \mathrm{lb}$ in 3 months, take a brisk walk twice per week for at least 1 hour). Patients will be encouraged to plan when, and where, and how often each week, they will perform the behaviour (e.g. walking at $3 \mathrm{pm}$ on Monday and Wednesday). Some patients will be encouraged to set a reward for effort or progress towards their goal or to access relevant social support. Patients will be encouraged to monitor behaviour and/or outcome (e.g. weight) closely and/or to complete if-then (implementation intention [25]) plans so they have a backup to their initial behavioural change plan. This is not an exhaustive list from the BCT taxonomy [23], and the full range of cognitive and behavioural techniques are used according to the different consultations and needs of patients. Examples of technique usage are given in Additional file 1. Lastly, communication with primary and secondary care colleagues will be conducted to inform them of intervention with the aim of enabling further support for change when patients attend other NHS appointments.

\section{Number and delivery mode for consultation sessions}

Up to 12 consultation sessions will be available for patients by phone or face-to-face appointments in the 
hospital site. However, in practice, most participants will be likely to receive fewer consultations than this. Followup sessions will be negotiated with the patient depending on a number of factors including:

- Patient preference (e.g. contact by telephone due to location of hospital clinic or prefer no follow-up if not wishing to pursue lifestyle change goals)

- Feedback from patients regarding goal attainment/ difficulty as patients' progressed through behavioural change attempts (e.g. patients not achieving goals or feeling demotivated could be brought back in for further face-to-face consultation)

- Clinical expertise of the Health Psychologist (e.g. identifying patients who likely require a greater level of input)

\section{Service evaluation \\ Procedures}

Data collection procedures are dependent on the type of data being extracted for evaluation. Table 1 below summarises procedures for collecting, analysing, and reporting each indicator for the service evaluation. All information is entered into routine databases that are used for service delivery. Data extraction is via an audit of this information for the duration of the service delivery period (at the end of proof-of-concept pilot).

\section{Patient experience survey}

As described in Table 1, consenting patients who receive at least one lifestyle consultation will be sent an anonymous patient experience survey. This will collect information through eight items including: age (patients mark this using an $X$ on a ruled line), their memory of taking part in the consultation (yes/no/not sure), their satisfaction with the service (5-point Likert scale: very satisfied/ satisfied/neither satisfied or unsatisfied/unsatisfied/very unsatisfied), their perception of benefit (yes/no/not sure) and would they recommend to other men in a similar position (yes/no/not sure). Patients will be also asked open-ended questions about what they most liked/disliked about aspects of service. Space for written comments is also provided with each question. The survey is sent out 2-4 weeks after the first appointment and returned via a prepaid envelope. Analysis is described in Table 1.

\section{Staff survey}

As described in Table 1 consenting staff from the Department of Urology will be sent the knowledge, attitudes and practice survey by email. This collects 18 data items including workplace demographics (4 items)-(i) clinical role (consultant/CNS); (ii) level of experience (less than 5 years/5-10 years/10 years or more); (iii) working hours (full/part-time) and (iv) gender (male/female). Knowledge, attitude and practice (14 items) were created by the research team to assess agreement with statements about lifestyle change. Staff will be first advised:

Please tell us how much you agree with the following statements about lifestyle change. By lifestyle change we mean anything that your patients can do to promote their own health and wellbeing. This could include general changes that most health professionals might recommend for living a healthy lifestyle, or specific changes, that could help patients manage symptoms or improve the effectiveness of the treatment you recommend for them. Some examples: cutting down on alcohol or caffeine, stopping smoking, taking more exercise, improving their diet, taking medication as prescribed and taking steps to managing stress etc.

The choice of items was guided by constructs from Theory Domains Framework (TDF) [26], which is a theoretical framework developed through expert consensus and factor analysis. It uses psychological theory to explain the facilitators and barriers of health professional practice (largely focused on provision of lifestyle change advice and support). TDF has previously been used to assess implementation of lifestyle change practice across a number of clinical areas [27].

Following iterative review with the research team, 14 items were developed to assess the following facets: knowledge; skills; social/professional role and identity; beliefs about capabilities; optimism; beliefs about consequences; reinforcement; intentions; goals; memory, attention and decision processes; environmental context and resources; social influences; emotion and behavioural regulation. The item wording is available in Additional file 2. All knowledge, attitude and practice items were rated using a 7-point Likert scale from strongly disagree to strongly agree. Analysis is described in Table 1.

\section{Lifestyle survey}

As described in Table 1, all patients will complete a short lifestyle survey prior to receiving the intervention and at around 3 months follow-up. This will collect information about 15 items focussing on the following behaviours:

- Smoking (2 items): Patients will be asked 'Do you smoke tobacco?' and respond as current smoker/ ex-smoker/no (i.e. never smoker; current smokers write down number smoked per day)

- Alcohol (3 items): Patients will be asked 'Do you drink alcohol?' and respond as most weeks/occasionally/no (i.e. non-drinker; current 
Table 1 Summary of the service evaluation procedures

\begin{tabular}{|c|c|}
\hline Data collection indicator & Method of data collection \\
\hline \multicolumn{2}{|l|}{ Acceptability indicators } \\
\hline $\begin{array}{l}\text { (i) Uptake to the service from } \\
\text { men with a negative } \\
\text { cancer screen }\end{array}$ & $\begin{array}{l}\text { Number of men receiving a TRUS biopsy who are invited to } \\
\text { take part in the service via CNS face-to-face contact is logged } \\
\text { via a routine audit database. Those who access at least one } \\
\text { appointment for lifestyle change will be used as positive for } \\
\text { uptake }{ }^{a} \text {. }\end{array}$ \\
\hline
\end{tabular}

(ii) Uptake to service from men with a positive cancer screen

(iii) Difference in uptake using socio-demographic and clinical characteristics of patients

(iv) Consent for service evaluation

(v) Patient experience and satisfaction with the service

Feasibility indicators

(i) Number and duration of appointment(s)

(ii) Number and type of behaviours discussed

(iii) Number of lifestyle change goals set

(iv) Length of time taken to compose letters previous calendar year (choosing an active surveillance protocol for cancer management) who are invited to take part in the service via patient letter is logged via a routine audit database Those who access at least one appointment for lifestyle change will be used as positive for uptake ${ }^{a}$.

Age (at invite for appointment), deprivation category summary and logged via a routine audit database ${ }^{a}$.

Patients are asked to provide consent to be involved in the service evaluation during their first lifestyle appointment. Numbers of men consenting logged via a routine audit database ${ }^{a}$.

All patients are sent a short self-completion postal survey to gather information on their experiences of the service (patient experience survey). Data collection is via a postal questionnaire, which is sent to them along with a covering letter, and is returned via a freepost envelope. Information is entered into a separate database. The survey asks for a response

(i.e. tick box and return of survey) even if the patient decides not to participate.

More detailed information below. for each patient is logged via a routine audit database ${ }^{a}$.

A record of the number of health issues and behaviours via a routine audit database. These are split into primary and discussion this would be coded as primary with diet, physical activity and alcohol use coded as secondary areas).

A record of the number and type of goals set by patients is logged via a routine audit database . $^{\mathrm{a}}$ via a routine audit database
Timing of data collection Planned analysis and reporting

Ongoing throughout service delivery. Descriptive analysis using Excel. Reported as proportion using numerical units and percentages.

Ongoing throughout service delivery. Descriptive analysis using Excel. Reported as proportion using frequency counts with percentages. (cancer/no cancer diagnosis) are taken from patient information

Each appointment date, length and type (face-to-face or telephone) (amenable to change) that are discussed with patients is logged secondary issues/behaviour (e.g. if weight loss is the main area of

Time taken to compose patient letters is logged for each patient
Ongoing throughout service delivery. Ongoing throughout service delivery

Patients are sent an anonymous

questionnaire 2-4 weeks after their first appointment.

Ongoing throughout service delivery

Ongoing throughout service delivery
Logistic regression using STATA to use socio-demographic and clinical characteristics as predictors of accessing the service. Reported using odds ratios and $95 \%$ confidence intervals.

Ongoing throughout service delivery. Descriptive analysis using Excel. Reported as proportion using frequency counts with percentages.

Descriptive analysis using Excel.

Reported as proportion using frequency counts with percentages.

Satisfaction data reported as mean (s.d.).

Open-ended comments analysed thematically

(with counts) and a selection reported as direct quotations.

Descriptive analysis using Excel. Reported as median number, length with IQR and type of appointment using frequency counts with percentages.

Descriptive analysis using Excel. Reported as median tota number (and for each behaviour) using frequency counts with percentages.

Descriptive analysis using Excel. Reported using frequency counts with percentages. 
Table 1 Summary of the service evaluation procedures (Continued)

\begin{tabular}{|c|c|c|c|}
\hline $\begin{array}{l}\text { (v) Changes to health } \\
\text { behaviours }\end{array}$ & $\begin{array}{l}\text { All patients taking part in the TRUS biopsy procedure are sent } \\
\text { a short self-completion lifestyle survey (lifestyle survey as par } \\
\text { covering several items (see detailed information below)). } \\
\text { This is sent to them along with a covering letter describing } \\
\text { the TRUS procedure (routine practice). Patients return this } \\
\text { survey in person to the CNS at the first appointment who } \\
\text { passes this information on the Health Psychologist. In some } \\
\text { cases, patients may complete the survey during the first } \\
\text { appointment (if not otherwise completed). } \\
\text { Active surveillance patients receive the lifestyle survey via a } \\
\text { letter confirming their appointment for a lifestyle consultation. } \\
\text { They are asked to bring the survey with them to their } \\
\text { appointment. In some cases, patients may complete the survey } \\
\text { during the first appointment (if not otherwise completed). } \\
\text { For repeat data collection, a postal survey is sent out to patients. } \\
\text { If patients have failed to respond within } 2-4 \text { weeks, up to } 3 \\
\text { phone calls are made to remind the patient about completion } \\
\text { of the survey. The repeat survey can be completed over the } \\
\text { phone during this call if preferred. } \\
\text { Patients are asked to provide consent to be involved in the } \\
\text { service evaluation during their first lifestyle appointment. } \\
\text { Information from the lifestyle survey is entered into a separate } \\
\text { database. } \\
\text { More detailed information below. }\end{array}$ & $\begin{array}{l}\text { For TRUS patients, the lifestyle survey } \\
\text { is completed prior to attending their } \\
\text { biopsy appointment. } \\
\text { For active surveillance patients, the } \\
\text { lifestyle survey is completed prior to } \\
\text { their first consultation appointment. } \\
\text { A repeat survey is completed } \\
\text { approximately } 3 \text { months following } \\
\text { their first appointment to assess any } \\
\text { pre-post changes. }\end{array}$ & $\begin{array}{l}\text { Descriptive analysis using Excel. } \\
\text { Using a coding system patient lifestyle change from } \\
\text { pre-post is coded as worse, no change, moderate or } \\
\text { substantial change in their primary and secondary } \\
\text { health behaviour areas (those discussed during the } \\
\text { consultation). Reported using frequency counts } \\
\text { with percentages. } \\
\text { See more detailed information below. }\end{array}$ \\
\hline $\begin{array}{l}\text { (vi) Clinical staff knowledge, } \\
\text { attitudes and practices } \\
\text { regarding lifestyle } \\
\text { change practice }\end{array}$ & $\begin{array}{l}\text { Questionnaire sent by email via to all consultant urologists and } \\
\text { clinical nurse specialists in the Department. Data collection via } \\
\text { online Survey Monkey. Information is entered into a separate } \\
\text { database. } \\
\text { Staff consent to be involved in the survey. Consent is implicit } \\
\text { and confirmed via their participation in the survey. Information } \\
\text { is collected anonymously. }\end{array}$ & $\begin{array}{l}\text { Sent approximately half way into } \\
\text { proof-of-concept pilot. } \\
\text { Reminder email sent } 2-4 \text { weeks later } \\
\text { requesting response. }\end{array}$ & $\begin{array}{l}\text { Descriptive analysis using Excel. } \\
\text { Knowledge, attitude and practice information reported } \\
\text { via mean (s.d.) for each item. } \\
\text { Open-ended comments analysed thematically (with counts) } \\
\text { and a selection reported as direct quotations. }\end{array}$ \\
\hline
\end{tabular}


drinkers to write down the highest number of units consumed per day and units consumed per week)

- Fruit and vegetable consumption (2 items): Patients will be asked how many portions of fruit and vegetables they consume in separate questions and report number of each consumed per day; for analysis, figures are added for total consumption

- Height (1 item) and weight (1 item): Weight is a relevant outcome, and this also allows for calculating body mass index. Patients will be also asked when was the last time they weighed themselves/were weighed (1 item with possible responses: within the last month/within the last 6 months/more than 6 months ago/don't know)

- Caffeine intake (1 item): Patients will write down the number of caffeinated products consumed by viewing a list of tea/coffee/cans of cola/energy $\operatorname{drink}(\mathrm{s}) /$ bars of chocolate (plain/milk). The total daily caffeine intake will be calculated by the following using data from the conversion information cited in Knight et al. [26] (e.g. number of tea mugs $\times 60 \mathrm{mg}$ and then added for together for each product to get a total mg of caffeine)

- Physical activity (2 items): Patients will be asked separately 'On how many days have you been physically active for a total of 30 min or more in the PAST WEEK?' and 'On how many days did you do physical activity that strengthened your muscles in the PAST WEEK?'. There is an explanation of what intensity is required (noticeable increase breathing/ slow walking does not count) and that 10 -min bout of activity is the minimum needed for inclusion

- Stress management (1 item): Patients will be asked 'What do you do to help you manage STRESS?' and respond by ticking agreement with a list of common techniques (e.g. say no to things/take control of difficult things/express your feelings/accept things you can't change/make time to relax and enjoy life) with space for other (give details) or not relevant to me

- Worthwhile activities (1 item): Patients will be asked 'How much do you take part in activities in your life that are worthwhile TO YOU?' and will respond via a 5-point Likert scale: none of the time/a little of the time/some of the time/most of the time/all of the time.

The lifestyle survey was developed as a pragmatic method for assessing behaviours quickly. Questions are worded to be as clear as possible and using written and visual information to improve accuracy of calculations (e.g. providing a visual of typical drinks and unit calculations for each next to the alcohol questions).
The survey was developed iteratively (first, with the research team and, second, through a pilot with eight TRUS biopsy patients routinely attended the urology clinic, who were not receiving the intervention described above). Patients reviewed earlier drafts of questions by completing the survey. Patients were asked to give feedback, while they waited to see the CNS. Time for completion was recorded for each patient, and patients were asked verbally to explain questions they were not sure about or had trouble with, questions they did not want to answer and how accurate and truthful they felt their responses had been, as well as any other comments.

\section{Analysis}

As described in Table 1, all data from the lifestyle survey will be entered into a spreadsheet as surveys are returned. To assess change from pre-post across these diverse behaviours, each item will be coded as worse, no change, moderate or substantial change. The criteria for coding and rationale are explained fully in Table 2 with details in Additional file 3. Criteria are focused on guidelines from the UK on optimal performance of health behaviours such as a reduction of alcohol units to within weekly national guidelines for males (where exceeding guidance prior to the consultation) was considered a substantial change.

When reporting change in lifestyle behaviours, each patient's own primary (most important or topic encompassing most time during the consultation) and secondary health behaviour topics will be reported only (i.e. across the range of possible health topics, we will report the number and proportion showing change/no change in an area discussed during contact with the service). This will provide information on potential impact of the teachable moment intervention on lifestyle behaviours across the spectrum discussed.

\section{Audit of routine patient database}

A routine data collection database was developed to be used for service delivery. However, indicators that will be captured here include the following items that are reported on below (required to assess feasibility and acceptability of the service):

i) Of each patient who was invited whether they accepted and received an appointment with the Health Psychologist

ii) Each patient's socio-demographic and clinical characteristics

iii) Whether consent for service evaluation was provided

iv) The total number of, and duration of, appointment(s) with the Health Psychologist 
Table 2 Summary of the coding system for the lifestyle change outcomes

\begin{tabular}{|c|c|c|c|c|c|c|c|}
\hline Behaviour/outcome & Units of measurement & Comment & Worse & No change & Moderate change & Substantial change & Evidence for choices \\
\hline Smoking status & $\begin{array}{l}\text { Current smoker, } \\
\text { ex-smoker, non-smoker }\end{array}$ & & $\begin{array}{l}\text { Ex- and non-smoker } \\
\text { became a smoker }\end{array}$ & $\begin{array}{l}\text { No change to } \\
\text { current smokers } \\
\text { smoking status }\end{array}$ & $\mathrm{n} / \mathrm{a}$ & $\begin{array}{l}\text { From initial smoker status becomes } \\
\text { ex-smoker at follow-up }\end{array}$ & \\
\hline Smoking amount & $\begin{array}{l}\text { How many smoked } \\
\text { per day (including } \\
\text { cigarettes, roll-ups, } \\
\text { cigars, pipes)? }\end{array}$ & $\begin{array}{l}\text { Only relevant to } \\
\text { current smokers }\end{array}$ & $\begin{array}{l}\text { Increased number } \\
\text { smoked per day at } \\
\text { follow-up }\end{array}$ & $\begin{array}{l}\text { No change to } \\
\text { number smoked } \\
\text { per day at follow-up }\end{array}$ & $\begin{array}{l}\geq 50 \% \text { reduction to } \\
\text { number smoked } \\
\text { per day at follow-up }\end{array}$ & $\begin{array}{l}\text { From initial smoker status becomes } \\
\text { ex-smoker at follow-up }\end{array}$ & $\begin{array}{l}\text { NICE (2013) guidance } \\
\text { on harm reduction for } \\
\text { tobacco }\end{array}$ \\
\hline Alcohol status & $\begin{array}{l}\text { Drink alcohol? } \\
\text { Most weeks, } \\
\text { Occasion-ally, } \\
\text { No }\end{array}$ & & $\begin{array}{l}\text { Non-drinker became } \\
\text { occasional/most } \\
\text { weeks drinker } \\
\text { OR } \\
\text { Occasional drinker } \\
\text { became most weeks } \\
\text { drinker }\end{array}$ & $\begin{array}{l}\text { No change to } \\
\text { current drinking } \\
\text { status }\end{array}$ & $\begin{array}{l}\text { Occasional drinker } \\
\text { becomes non-drinker } \\
\text { OR }\end{array}$ & $\begin{array}{l}\text { Most weeks drinker becomes } \\
\text { occasional or non-drinker }\end{array}$ & $\begin{array}{l}\text { Recommendation } \\
\text { from the European } \\
\text { Code Against Cancer }\end{array}$ \\
\hline Alcohol units & $\begin{array}{l}\text { Most units drunk } \\
\text { per day }\end{array}$ & $\begin{array}{l}\text { Only relevant to } \\
\text { current drinkers }\end{array}$ & $\begin{array}{l}\text { Increased number } \\
\text { of units per day at } \\
\text { follow-up }\end{array}$ & $\begin{array}{l}\text { No change to units } \\
\text { drunk }\end{array}$ & $\begin{array}{l}\text { Some reduction- } \\
\leq 50 \% \text { in units drunk } \\
\text { per day at follow-up }\end{array}$ & $\begin{array}{l}\text { Drinker exceeding daily limit at } \\
\text { baseline is under daily limit at } \\
\text { follow-up (i.e. } \leq 4 \text { units per day) } \\
\text { OR } \\
\geq 50 \% \text { reduction in units drunk } \\
\text { per day at follow-up }\end{array}$ & $\begin{array}{l}\text { Alcohol unit } \\
\text { guidelines from } \\
\text { UK Government }^{c}\end{array}$ \\
\hline Alcohol units & $\begin{array}{l}\text { Total units drunk } \\
\text { per week }\end{array}$ & $\begin{array}{l}\text { Only relevant to } \\
\text { current drinkers }\end{array}$ & $\begin{array}{l}\text { Increased number } \\
\text { of units per day at } \\
\text { follow-up }\end{array}$ & $\begin{array}{l}\text { No change to units } \\
\text { drunk }\end{array}$ & $\begin{array}{l}\text { Some reduction-- } \\
\leq 50 \% \text { in units drunk } \\
\text { per week at follow-up }\end{array}$ & $\begin{array}{l}\text { Drinker exceeding weekly limit at } \\
\text { baseline is under weekly limit at } \\
\text { follow-up (i.e. } \leq 21 \text { units per week) } \\
\text { OR } \\
\geq 50 \% \text { reduction in units drunk } \\
\text { per week at follow-up }\end{array}$ & $\begin{array}{l}\text { Alcohol unit } \\
\text { guidelines from } \\
\text { UK Government }\end{array}$ \\
\hline Weight loss & $\%$ weight loss (in kg) & $\begin{array}{l}\text { All men-but } \\
\text { particularly relevant } \\
\text { to overweight/obese } \\
\text { men }\end{array}$ & Increase in weight & $\begin{array}{l}\text { No change to } \\
\text { weight }\end{array}$ & $\begin{array}{l}\text { Some reduction in } \\
\text { weight }(<5 \% \text { at } \\
\text { follow-up) }\end{array}$ & $\begin{array}{l}\text { Reduction in weight is } \geq 5 \% \text { at } \\
\text { follow-up }\end{array}$ & $\begin{array}{l}\text { Research showing a } \\
5 \% \text { reduction in } \\
\text { weight leads to health } \\
\text { benefit }^{d}\end{array}$ \\
\hline Body mass index & $\begin{array}{l}\text { BMI (i.e. weight } \\
(\mathrm{kg}) / \text { height }\left(\mathrm{m}^{2}\right) \text { ) }\end{array}$ & $\begin{array}{l}\text { All men_but } \\
\text { particularly relevant } \\
\text { to overweight/obese } \\
\text { men }\end{array}$ & Increase in BMI & No change to BMI & $\begin{array}{l}\text { Reduction in } \mathrm{BMl} \\
\text { maps onto a }<5 \% \\
\text { reduction in weight } \\
\text { at follow-up }\end{array}$ & $\begin{array}{l}\text { Change in BMI category } \\
\text { (i.e. from Obese to overweight or } \\
\text { from overweight to healthy } \\
\text { weight range) } \\
\text { OR } \\
\text { Reduction in BMI maps onto a } \geq 5 \% \\
\text { reduction in weight at follow-up }\end{array}$ & $\begin{array}{l}\text { Research showing a } \\
5 \% \text { reduction in } \\
\text { weight leads to health }_{\text {benefit }^{d}}\end{array}$ \\
\hline $\begin{array}{l}\text { Physical activity } \\
\text { (cardiovascular) }\end{array}$ & $\begin{array}{l}\text { Number of days active } \\
\text { for at least } 30 \text { min } \\
\text { ( } \geq \text { moderate intensity) }\end{array}$ & All men & $\begin{array}{l}\text { Any reduction in } \\
\text { number of active } \\
\text { days (CV) }\end{array}$ & $\begin{array}{l}\text { No change to } \\
\text { number of active } \\
\text { days (MS) }\end{array}$ & $\begin{array}{l}\text { Increase in number } \\
\text { of active days } \\
\text { (CV) by } 1\end{array}$ & $\begin{array}{l}\text { Increase in number of active days } \\
\text { (CV) by }>1 \text { day } \\
\text { OR } \\
\text { Achieves weekly physical activity } \\
\text { (CV) guidelines day at follow-up } \\
\text { (only those not achieving them } \\
\text { at baseline) }\end{array}$ & $\begin{array}{l}\text { UK physical activity } \\
\text { guidelines for adults }\end{array}$ \\
\hline
\end{tabular}


Table 2 Summary of the coding system for the lifestyle change outcomes (Continued)

\begin{tabular}{|c|c|c|c|c|c|c|c|}
\hline $\begin{array}{l}\text { Physical activity } \\
\text { (muscle } \\
\text { strengthening) }\end{array}$ & $\begin{array}{l}\text { Number of days any } \\
\text { muscle strengthening } \\
\text { activity }\end{array}$ & All men & $\begin{array}{l}\text { Any reduction in } \\
\text { number of active } \\
\text { days (MS) }\end{array}$ & $\begin{array}{l}\text { No change to } \\
\text { number of active } \\
\text { days (MS) }\end{array}$ & $\begin{array}{l}\text { Increase in number of } \\
\text { active days (MS) by } 1\end{array}$ & $\begin{array}{l}\text { Increase in number of active days } \\
\text { (MS) by }>1 \text { day } \\
\text { OR } \\
\text { Achieves weekly physical activity } \\
\text { (MS) guidelines day at follow-up } \\
\text { (only those not achieving them } \\
\text { at baseline) }\end{array}$ & $\begin{array}{l}\text { UK physical activity } \\
\text { guidelines for adults }\end{array}$ \\
\hline $\begin{array}{l}\text { Fruit and vegetable } \\
\text { intake }\end{array}$ & $\begin{array}{l}\text { Total daily portions of } \\
\text { fruit and vegetables }\end{array}$ & All men & $\begin{array}{l}\text { Any reduction in } \\
\text { number of fruits and } \\
\text { vegetables eaten }\end{array}$ & $\begin{array}{l}\text { No change to } \\
\text { number of fruits } \\
\text { and vegetables } \\
\text { eaten }\end{array}$ & $\begin{array}{l}\text { Increase in portions of } \\
\text { fruits and vegetable by } \\
1 \text { per day }\end{array}$ & $\begin{array}{l}\text { Increase in portions of fruits and } \\
\text { vegetable by }>1 \text { per day } \\
\text { OR } \\
\text { Achieves five portions FV per day } \\
\text { at follow-up (only those not } \\
\text { achieving } 5 \text { a day at baseline) }\end{array}$ & $\begin{array}{l}\text { Current NHS guidance } \\
\text { plus research evidence }\end{array}$ \\
\hline
\end{tabular}

This is a research area they recommended. However, it is also noted that people from routine and manual groups are more likely to cut down first, rather than stop 'abruptly', and intervention studies showed a positive effect where the primary outcome was to help people cut down prior to stopping smoking (mainly cognitive behavioural therapy and counselling)

${ }^{\mathrm{b} A c c o r d i n g}$ to the European code against cancer [34], if you drink alcohol of any type, limit your intake. Not drinking alcohol is better for cancer prevention

'The Royal College of Physicians evidence base for alcohol guidelines [35]

${ }^{\mathrm{d}}$ The following studies have shown significant decreases in triglycerides, waist circumference, glucose, insulin and blood pressure following a minimum $5 \%$ weight-loss [36, 37]

e Recommendations from the four Chief Medical Officer's in the UK [38] include $2 \frac{1}{2} \mathrm{~h}$ CV per week (i.e. $5 * 30 \mathrm{~min}$ ). Adults should also undertake physical activity to improve muscle strength on at least 2 days a week.

There are also guidelines for older adults (including balance exercises); this was not included in the lifestyle survey. Sedentary time was not included either despite being part of the new guidelines

fWang et al. [39] showed a threshold for all-cause mortality from fruits and vegetable consumption of five per day 
v) The number and type of behaviours discussed with the Health Psychologist

vi) The number and nature of lifestyle change goals set

vii)The length of time taken to compose letters regarding appointments

Table 1 below summarises procedures for collecting, analysing and reporting each indicator for the service evaluation. Data extraction was via audit process and service evaluation for the duration of the service delivery period (at the end of proof-of-concept pilot).

\section{Discussion}

This work describes the initiative to introduce lifestyle consultations for behaviour change that take advantage of cancer testing and/or diagnosis as a teachable moment for change. As a proof-of-concept pilot, the scope of this work is to assess the feasibility and accessibility of such a development in a busy urology service (providing secondary care cancer services).

In this pilot study, a Health Psychologist is used to conduct lifestyle consultations, and the patient experience data and lifestyle survey audit will provide information regarding the feasibility of this approach. However, in previous work using 'teachable moments' in a trial within colorectal cancer screening 'trained lifestyle counsellors' were used [17]. The extent to which existing clinical staff within secondary care cancer settings (e.g. consultant doctors and CNS) could be used is an important area for exploration. However, previous translational evidence has shown such staff often struggle with elements of implementing lifestyle change with patients (particularly using MI) [28]. Our study uses a staff survey with existing clinical staff to tease out whether knowledge, attitudes and practices might make integrating lifestyle change into routine health service conversations more or less feasible for these professionals.

The importance of testing the feasibility and acceptability of this approach to integrating lifestyle change into practice should not be underestimated. Numerous authors and public agencies have recognised the problems in translating the results of high-quality clinical trials of preventative approaches into practice $[29,30]$. As described by Basch et al. (as cited in Glasgow and colleagues [29]), 'a program cannot be effective if it is not implemented' (p. 1256). This type of proof-of-concept testing should, therefore, be welcome and, if successful, should offer service managers and clinicians reassurance that such services add rather than take away from the routine and person-centred clinical cancer care they provide. It should also be recognised that any lifestyle change discussion following a consultation regarding a cancer diagnosis needs to be dealt with required care to take the emotional state of the patient into account and avoid any possibility for implying blame in the patient's health status.

Indeed, this development should not be seen in isolation, but rather in the context of the national public policy framework operating within Scotland, which places early detection, and the prevention of cancer, as well as timely and high-quality treatment and posttreatment as central to the agenda for service innovation and improvement $[31,32]$. There are also numerous other cancer testing, screening and treatment settings in which lifestyle change represents an important part of improving patient outcomes (both from a preventative and treatment perspective). Overall, if successful, this work could present one viable option for integrating preventative approaches into such services more widely. We believe that new service inputs into the health care system can be introduced as pragmatic, measurable elements which are certainly amenable to evaluation and thereby contribute to expanding the evidence base. However, in order to achieve wider implementation, effectiveness of this service would need to be shown through a larger study with multiple Health Psychologists delivering the service and testing the intervention through a randomised trial.

\section{Additional files}

Additional file 1: Examples of other behaviour change techniques used in the first and subsequent consultations*. (DOC $24 \mathrm{~kb}$ )

Additional file 2: Staff survey knowledge, attitudes and practice items (developed using Theory Domains Framework constructs) [33]. (DOC 24 kb)

Additional file 3: Coding criteria for lifestyle change outcomes (pre-post). (DOC 23 kb)

\section{Abbreviations}

BCTs: Behaviour change techniques; CAP: Cancer of the prostate; CNS: Clinical nurse specialists; Ml: Motivational interviewing; MRI: Magnetic resonance imaging; TDF: Theory Domains Framework; TRUS: Transrectal ultrasound; UK: United Kingdom

\section{Acknowledgements \\ The project team would like to acknowledge the contribution made to conceptualising the proof-of-concept trial from the clinical colleagues within the Department of Urology, NHS Fife, in particular Debbie Mccrae; from the colleagues within the Research and Development Team, NHS Fife, in particular Dr David Chinn; and from the colleagues within the eHealth Quality \& Governance Team, NHS Fife, in particular, Una Hill.}

\section{Funding}

The service and evaluation is funded by the Scottish Government through the Detect Cancer Early Programme. The Scottish Government has no role in the study design, data collection or analysis, decision to publish or preparation of the manuscript.

\section{Authors' contributions}

AL was responsible for the development of the procedures used for the service design and service evaluation procedures and conducted all data collection and service delivery and was the primary author co-ordinating this manuscript. SL is the urology clinical lead on the project. HD contributed to the design of the intervention and evaluation. GH is the co-PI of the research project, joint supervision and editor of the manuscript. GO is the co-PI of the research project, joint supervision and editor of the manuscript. NH was 
responsible for sourcing the funding and assuring engagement with the Fife Detect Cancer Early Programme Board. All authors reviewed and commented on the drafts of the manuscript and approved the final version.

\section{Authors' information}

AL is a Health Psychologist and Researcher. She has worked in several NHS positions and completed a PhD addressing the use of theoretically based interventions to increase postnatal physical activity.

$S L$ is a Consultant Urological Surgeon within NHS Fife with a particular interest in laparoscopic surgery and the development of new models of follow-up cancer care.

$H D$ is a Health Psychologist with NHS Fife. She is trained as an MI Coach. Her PhD explored lifestyle change among men with cancer.

$\mathrm{GH}$ is a Professor of Health Psychology at University of St Andrews, Chair of Research Committee for European Association of Communication in Healthcare and Honorary Consultant Clinical Psychologist at the Western General Hospital, Edinburgh.

GO is a Senior Lecturer of Health Psychology at University of St Andrews. Her interests include conducting applied research to help inform psychological support programmes for behaviour change and emotional support, particularly among cancer patients and survivors.

$\mathrm{NH}$ is a Consultant in Public Health Medicine with a remit for the awareness-raising and prevention of cancer within the Detect Cancer Early programme in Fife.

\section{Competing interests}

The authors declare that they have no competing interests.

\section{Ethics approval and consent to participate}

Ethical approval for the evaluation was obtained by the East of Scotland Research Ethics Service (EOSRES) Ethics Committee (reference no. CYA/AG/ 14/GA/119). The Scientific Officer advised the evaluation does not require NHS ethical review under the terms of the Governance Arrangements for Research Ethics Committees.

All patients included in the evaluation provided consent to participate. The management and data storage took place at the Queen Margaret Hospital, NHS Fife. The analysis of the data (following removal of identifiable information) took place at the School of Medicine, University of St Andrews.

\section{Authors' statement}

The protocol has been submitted after the recruitment of the study is completed and therefore is outside the journal's normal policies. However, the following extenuating circumstances were considered: the short-term nature of the study as a proof-of-concept service improvement pilot and that the protocol was submitted before the data analysis. The dissemination of this research to the clinical team and to the funders has been agreed in advance and will include a final report and presentation.

\section{Author details}

${ }^{1}$ Department of Urology, NHS Fife, Kirkcaldy, UK. ${ }^{2}$ School of Medicine, University of St Andrews, Fife, St Andrews, Scotland KY16 9TF, UK. ${ }^{3}$ Department of Psychology, NHS Fife, Kirkcaldy, UK. ${ }^{4}$ Department of Public Health, NHS Fife, Kirkcaldy, UK.

\section{Received: 16 February 2016 Accepted: 28 September 2016} Published online: 21 October 2016

\section{References}

1. Parkin DM, Boyd L, Walker LC. The fraction of cancer attributable to lifestyle and environmental factors in the UK in 2010. Summary and conclusions. Br J Cancer. 2011;105(S2):S77-81.

2. World Health Organisation. GLOBOCAN 2012: Estimated Cancer Incidence, Mortality and Prevalence Worldwide in 2012. http://globocan.iarc.fr/Pages/ fact_sheets_cancer.aspx. Accessed 20 Jan 2016

3. Lawson PJ, Flocke SA. Teachable moments for health behavior change: a concept analysis. Patient Educ Couns. 2009. doi:10.1016/j.pec.2008.11.002.

4. McBride CM, Ostroff JS. Teachable moments for promoting smoking cessation: the context of cancer care and survivorship. Cancer Control. 2003;10:325-33.

5. Cancer Research UK. http://www.cancerresearchuk.org/health-professional/ cancer-statistics/statistics-by-cancer-type/prostate-cancer. Accessed 21 Jan 2016.
6. World Cancer Research Fund International. Diet, nutrition, physical activity and prostate cancer, 2014. http://www.wcrf.org/sites/default/files/ProstateCancer-2014-Report.pdf. Accessed 5 Dec 2015.

7. Cancer Research UK. Perceptions of risk survey 2008: key findings. http://www.cancerresearchuk.org/prod_consump/groups/cr_common/ @nre/@hea/documents/generalcontent/014219.pdf. Accessed 2 Feb 2016.

8. Stead M, Caswell S, Craigie AM, et al. Understanding the potential and challenges of adenoma treatment as a prevention opportunity: insights from the BeWEL formative study. Prev Med. 2012;54(1):97-103.

9. Hackshaw-McGeagh LE, Penfold CM, Walsh E, Donovan JL, Hamdy FC, Neal DE, JeffreysM, Martin RM, Lane A, and the ProtecT Study Group. Physical activity, alcohol consumption, BMI and smoking status before and after prostate cancer diagnosis in the ProtecT trial: opportunities for lifestyle modification. Int J Cancer. 2015; DOI: 10.1002/ijc.29514.

10. Lee AL, Leung S, Dale H, Ozakinci G, Humphris G. Opportunities for lifestyle change in cancer screening, testing and treatment settings: analysis of the needs of men undergoing testing for cancer of the prostate. Poster Presentation at the International Society for Behavioral Nutrition and Physical Activity (ISBNPA) Conference, Edinburgh; 2015.

11. Ornish D, Lin J, Chan JM, Epel E, Kemp C, Weidner G et al. Effect of comprehensive lifestyle changes on telomerase activity and telomere length in men with biopsy-proven low-risk prostate cancer: 5-year follow-up of a descriptive pilot study. Lancet Oncol. 2013;14(11):1112-20.

12. Moreira DM, Aronson WJ, Terris MK, et al. Cigarette smoking is associated with an increased risk of biochemical disease recurrence, metastasis, castration-resistant prostate cancer, and mortality after radical prostatectomy. Cancer. 120(2):197-20. doi: 10.1002/cncr.28423

13. Smith JA, Braunack-Mayer A, Wittert G. What do we know about men's help-seeking and health service use? Med J Aust. 2006;184(2):81-3.

14. Larsen IK, Grotmol T, Almendingen K, Hoff G. Impact of colorectal cancer screening on future lifestyle choices: a three-year randomized controlled trial. Clin Gastroenterol Hepatol. 2007:5(4):477-83.

15. Anderson AS, Caswell S, Wells M, Steele RJ. Obesity and lifestyle advice in colorectal cancer survivors-how well are clinicians prepared? Colorectal Dis. 2013;15(8):949-57. doi:10.1111/codi.12203.

16. Senore C, Giordano L, Bellisario C, Di Stefano F, Segnan N. Population based cancer screening programmes as a teachable moment for primary prevention interventions. A review of the literature. Front Oncol. 2012;2:45. doi:10.3389/fonc.2012.00045.

17. Craigie AM, Caswell S, Paterson C, Treweek S, Belch JJ, Daly F, Rodger J, Thompson J, Kirk A, Ludbrook A, Stead M, Wardle J, Steele RJ, Anderson AS. Study protocol for BeWEL: the impact of a BodyWEight and physicaL activity intervention on adults at risk of developing colorectal adenomas. BMC Public Health. 2011;11:184. doi:10.1186/1471-2458-11-184.

18. Robb KA, Power E, Kralj-Hans I, Atkin WS, Wardle J. The impact of individually-tailored lifestyle advice in the colorectal cancer screening context: a randomised pilot study in North-West London. Prev Med. 2010;51:505-8. doi:10.1016/j.ypmed.2010.10.002.

19. Caswell S, Anderson AS, Steele RJ. Bowel health to better health: a minimal contact lifestyle intervention for people at increased risk of colorectal cancer. Br J Nutr. 2009:102:1541-6. doi:10.1017/S0007114509990808.

20. Baker AH, Wardle J. Increasing fruit and vegetable intake among adults attending colorectal cancer screening: the efficacy of a brief tailored intervention. Cancer Epidemiol Biomarkers Prev. 2002;11:203-6.

21. Schröder FH, et al. Screening and prostate cancer mortality: results of the European Randomised Study of Screening for Prostate Cancer (ERSPC) at 13 years of follow-up. Lancet. 2014;384:2027-35.

22. ISD Scotland; http://www.isdscotland.org/Health-Topics/Cancer/CancerStatistics/Male-Genital-Organs/\#prostate. Accessed 10 Feb 2016.

23. Miller WR, Rollnick S. Motivational Interviewing: Helping People Change. 3rd ed. Guilford Press; 2012.

24. Michie S, Richardson M, Johnston M, Abraham C, Francis J, Hardeman W, Eccles MP, Cane J, Wood CE. The behavior change technique taxonomy (v1) of 93 hierarchically clustered techniques: building an international consensus for the reporting of behavior change interventions. Ann Behav Med. 2013:46(1):81-95.

25. Gollwitzer PM. Implementation intentions: strong effects of simple plans. Am Psychol. 1999:54:493-503.

26. Knight CA, Knight I, Mitchell DC, Zepp JE. Beverage caffeine intake in U.S. consumers and subpopulations of interest: estimates from the Share of Intake Panel survey. Food Chem Toxicol. 2004;24:1923-30. 
27. Phillips CJ, Marshall AP, Chaves NJ, Jankelowitz SK, Lin IB, Loy CT, et al. Experiences of using the Theoretical Domains Framework across diverse clinical environments: a qualitative study. J Multidiscip Healthc. 2015:8:139-46.

28. Whittemore R, Melkus G, Wagner J, et al. Translating the diabetes prevention program to primary care. Nurs Res. 2009;58:2-12.

29. Glasgow RE, Lichtenstein E, Marcus AC. Why don't we see more translation of health promotion research to practice? Rethinking the efficacy-toeffectiveness transition. Am J Public Health. 2003;93:8.

30. Green LW. Making research relevant: if it is an evidence-based practice, where's the practice-based evidence? Fam Pract. 2008;25 suppl 1:i20-4. doi:10.1093/fampra/cmn055.

31. Scottish Government. Better cancer care, an action plan. Edinburgh: Scottish Government; 2008

32. Scottish Government. Health promoting health service: action in acute care settings 2014. http://www.sehd.scot.nhs.uk/mels/CEL2008_14.pdf. Accessed 6 Dec 2015.

33. Francis JJ, O'Connor D, Curran J. Theories of behaviour change synthesised into a set of theoretical groupings: introducing a thematic series on the theoretical domains framework. Implement Sci. 2012;7:24.

34. World Health Organization. European Code Against Cancer 2003. http:// cancer-code-europe.iarc.fr/index.php/en/. Accessed 6 Dec 2015.

35. Royal College of Physicians. The evidence base for alcohol guidelines. 2011. http://www.publications.parliament.uk/pa/cm201012/cmselect/cmsctech/ writev/1536/ag22.htm RCP 2011. Accessed 21 Jan 2016.

36. Graffagnino CL, Falko JM, Londe ML, Shaumburg J, Hyek MF, Shaffer LE, Snow R, Caulin-Glaser T. Effect of a community-based weight management program on weight loss and cardiovascular disease risk. Obesity. 2006;14(2):280-88.

37. Villareal DT, Miller BV, Banks M, Fontana L, Sinacore DR, Klein S. Effect of lifestyle intervention on metabolic coronary heart disease risk factors in obese older adults. The American Journal of Clinical Nutrition. 2006;84(6):1317-23.

38. Chief Medical Officers Factsheet 4: Physical activity guidelines for Adults (19-64 years) 2014. https://www.gov.uk/government/uploads/system/uploads/ attachment_data/file/213740/dh_128145.pdf. Accessed 10 Feb 2016.

39. Wang Xia, Ouyang Yingying, Liu Jun, Zhu Minmin, Zhao Gang, Bao Wei et al. Fruit and vegetable consumption and mortality from all causes, cardiovascular disease, and cancer: systematic review and dose-response meta-analysis of prospective cohort studies BMJ 2014;349:94490.

\section{Submit your next manuscript to BioMed Central and we will help you at every step:}

- We accept pre-submission inquiries

- Our selector tool helps you to find the most relevant journal

- We provide round the clock customer support

- Convenient online submission

- Thorough peer review

- Inclusion in PubMed and all major indexing services

- Maximum visibility for your research

Submit your manuscript at wuw biomedcentral.com/submit

C) Biomed Central 